\title{
“Al-Arabiyyah Sahlah" Sebagai Label Perspektif Baru Dalam Menyongsong Pembelajaran Bahasa Arab Di Era
}

\author{
New Normal \\ Ayu Nur Islami ${ }^{1}$ \\ Program Studi Pendidikan Bahasa Arab IAIN Salatiga \\ E-mail: ayunurislami98@gmail.com
}

\begin{abstract}
This research was conducted by disseminating questionnaires and concluded that 23 out of 36 people assumed Arabic was difficult. This is what is behind the writing of this article. Kalam Allah and Rasulullah Arabic-speaking Apostles have been absolutely a guide to life, so muslims should try to learn it. If psychologically only Arabic is considered difficult, then it will be a inhibition of concern for many people to learn it. The purpose of this article was to renew the sensitivity of Arabic which could later become the main capital to mobilize interest and motivation for learners. In addition, methodological renewal is no less important, where the techniques and teaching methods of educators must be completely improved. Senior educators, students, even arabic language institutions must equip themselves with the right teaching competencies. Even this new normal era becomes both an opportunity and a challenge to fix it all. So there needs to be a deeper discussion to make it easier for the Al-Arabiyyah Sahlah (Arabic to be easy) to learn, as the Divine Kalam promises "And indeed, we have made it easy for the Qur'an to be warned, so will anyone take a lesson?"
\end{abstract}

Keyword : Al-Arabiyyah Sahlah, Perspective, Learning.

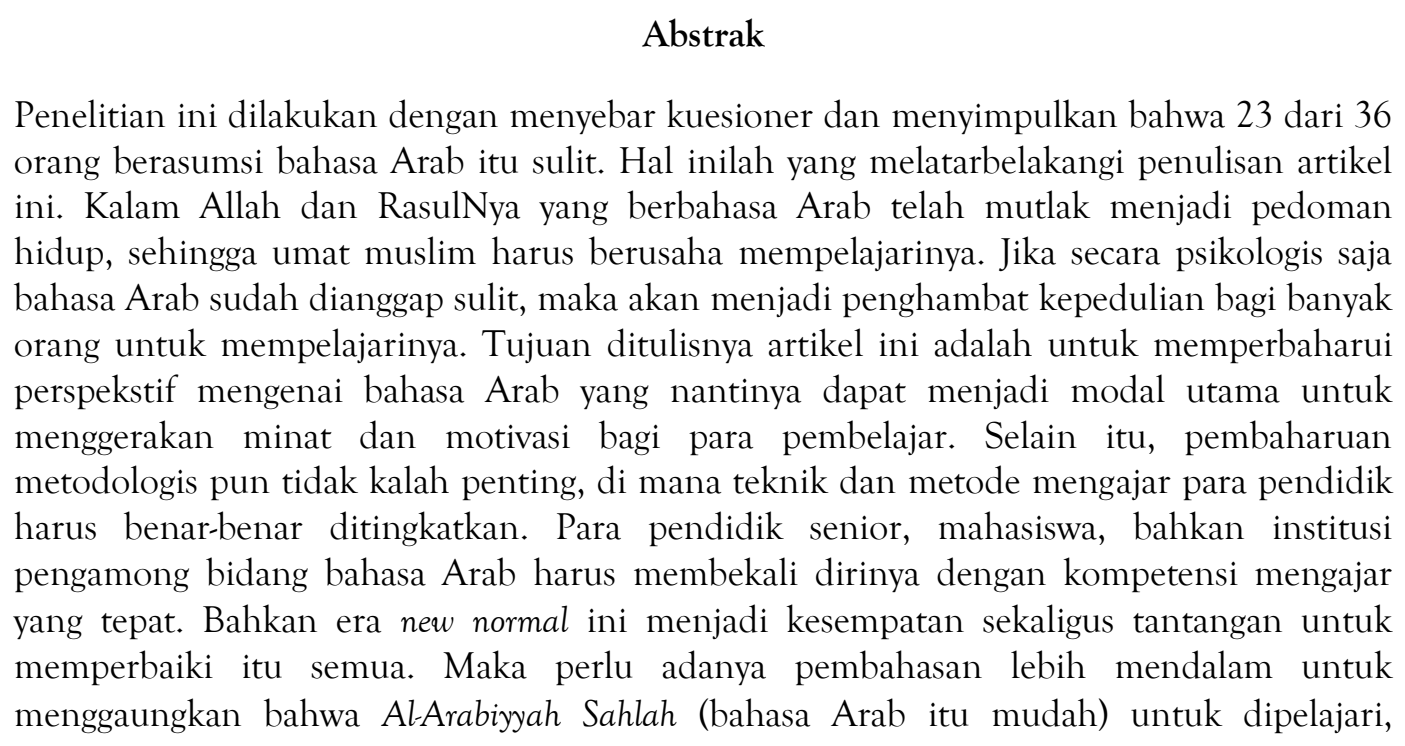


sebagaimana janji Kalam Ilahi "Dan sungguh, telah Kami mudahkan Al-Qur'an (yang berbahasa Arab) untuk peringatan, maka adakah orang yang mau mengambil pelajaran?"

Kata Kunci: Al-Arabiyyah Sahlah, Perspektif, Pembelajaran.

\section{Pendahuluan}

Bahasa Arab adalah salah satu ilmu penting yang harus dipelajari oleh kaum muslimin. Bagaimana tidak, tatanan hidup yang menjadi pedoman bagi kehidupan manusia adalah Al-Qur'an dan Hadits yang berbahasa Arab. Bukan hanya perihal religiusitas, era revolusi industri 4.0 ini juga mempengaruhi peran bahasa Arab yang harus dikuasai oleh banyak orang sebagai alat komunikasi jika ingin bergelut di dunia industri perdagangan atau pariwisata internasional khususnya negara-negara yang berbahasa Arab. Jika bahasa Arab mampu dikuasai oleh seseorang maka hal itu bukan hanya menjadi jendela tetapi justru menjadi pintu untuk mencapai kebahagiaan yang luar biasa baik untuk kepentingan duniawi maupun ukhrawi. Namun sayangnya, eksistensi bahasa Arab di sekitar kita menjadi kurang diminati. Banyak orang yang beranggapan bahwa bahasa Arab itu terlalu sulit untuk dipelajari dan dipahami hingga terjadilah eksklusifisme terhadap bahasa Arab. Anehnya lagi sebagaiamana dikutip dari Sulistiyani (2006: 49) meyatakan bahwa sebagian orang beropini jika salah dalam mengucapkan atau melafadzkan huruf Arab akan mendapat dosa.

Jika sulitnya matematika, kimia, fisika, dan ilmu hitungan lainnya orangorang rela untuk mencari guru bimbel, lalu bagaimana dengan sulitnya bahasa Arab? Apakah ada yang mencari guru bimbel bahasa Arab? Mungkin ada, tapi tidak seramai pelajaran lainnya. Eksistensi bahasa Arab juga nampaknya kalah dari bahasa Inggris, hal ini dapat kita lihat dari tempat kursus di Pare, Kediri di mana lembaga yang menyediakan kursus bahasa Arab masih bisa dihitung jari, kalah jauh dengan bahasa Inggris. Hal ini harusnya membuka peluang dan inovasi bagi para pegiat bahasa Arab untuk menciptakan wahana baru yang menyediakan akses dan fasilitas pembelajaran bahasa Arab. Jika menilik pada mahfudhzat "منّ وجد", lantas mengapa bahasa Arab masih sepi peminat? Anggapan doktrin bahwa bahasa Arab itu sulit menjadi faktor penyebab trauma psikologis pada seseorang bahkan 
Jurnal DinamikA

Volume 1 No. 2 (2020)

E-ISSN: 2723-1410

Website: https://jurnal.iainsalatiga.ac.id/index.php/dinamika/index

sebelum ia mempelajarinya hingga ia enggan mempelajarinya. Sementara itu, dalam realita penerapan pembelajarannya juga kurang dapat menarik minat dan semangat para pembelajar karena metode dan teknik yang digunakan kurang kreatif dan membosankan. Sehingga dari sini, dapat kita tarik 2 faktor utama yang menyebabkan bahasa Arab itu cenderung stagnan yaitu faktor psikologis dan metodologis.

Sebagaimana ada aksi maka akan ada reaksi. Ada masalah harusnya ditemukan solusinya. Jika secara doktrin membuat psikologis banyak orang terpengaruh untuk enggan mempelajari bahasa Arab maka solusinya adalah dengan mendatangkan doktrin baru yang mampu mengubah mindset sebelumnya. Maka diperlukan motivasi dan dalil rasionalitas yang mampu mengangkat kembali eksistensi bahasa Arab sebagai landasan dari doktrin baru. Para pegiat dan pengajar bahasa Arab harus berbekal dengan sejuta sumber dan motivasi serta alasan yang menganjurkan agar orang-orang mau mempelajari bahasa Arab, sebagai contoh misalnya: perkataan Umar radhiyallahu 'anhu "Pelajarilah bahasa Arab karena sesungguhnya bahasa Arab itu dapat mengokohkan akal dan menambah kehormatan” (Sa'id: 2017). Tidak cukup dengan doktrin semata, untuk memperbaharui eksistensi bahasa Arab juga dibutuhkan realita penerapannya. Pengajar, mahasiswa calon pengajar, bahkan lembaga institusi yang membidangi bahasa Arab harus benar-benar membekali dirinya dengan kompetensi dan keahlian berupa metode menarik dan kreatif yang mampu menggugah selera dan semangat belajar para pembelajar. Era new normal ini menjadi tantangan sekaligus kesempatan untuk mengenalkan bahwa bahasa Arab itu mudah. Dengan demikian, diharapkan anggapan semula yang mengatakan bahwa bahasa Arab itu sulit kini bisa berubah label menjadi bahasa Arab itu mudah (Al-Arabiyyah Sahlah).

\section{Metode Penelitian}

Metode yang digunakan dalam penelitian ini adalah metode deskriptif yaitu suatu metode dalam meneliti status sekelompok manusia, objek, kondisi, sistem pemikiran, ataupun suatu peristiwa pada masa sekarang yang bertujuan untuk 
membuat deskripsi, gambaran atau lukisan secara sistematis, faktual dan akurat mengenai fakta-fakta, sifat-sifat serta hubungan antar fenomena yang diselidiki (Susilana \& Johan, 2012: 75-76). Peneliti mencari fakta mengenai anggapan sebagian orang tentang belajar bahasa Arab kemudian mendeskripsikannya dan menghubungkannnya dengan beberapa solusi. Dalam penelitian ini, yang menjadi objek penelitian adalah pelajar dan mahasiswa yang pernah belajar bahasa Arab. Alat pengumpul data yang digunakan dalam penelitian ini adalah dengan membagikan kuesioner, yaitu teknik pengumpulan data yang dilakukan dengan cara memberi seperangkat pertanyaan atau pernyataan tertulis kepada responden untuk dijawabnya (Susilana \& Johan, 2012: 202) dan wawancara melalui media sosial kepada mahasiswa dan pelajar yang pernah belajar bahasa Arab. Teknik analisis data penelitian ini yaitu dengan mengumpulkan hasil kuesioner dan wawancara kemudian merumuskannya dalam bentuk tabel atau diagram dan disimpulkan secara deskriptif hingga memberikan beberapa masukan atau solusi atas fakta yang telah didapatkan yaitu dengan merujuk pada literatur yang berkaitan dengan masalah tersebut.

\section{Hasil Penelitian Dan Pembahasannya}

\section{Hasil}

\section{Perspektif tentang Bahasa Arab}

Perspektif adalah suatu pandangan dari suatu dasar pemikiran atau yang menjadi dasar pemikiran (Sari, 2016). Dari kuesioner yang telah disebar, 23 orang $(63,9 \%)$ dari 36 responden baik dari kalangan mahasiswa maupun pelajar yang pernah belajar bahasa Arab menganggap bahwa bahasa Arab itu sulit. Angka ini akan jauh lebih tinggi lagi jika kuesioner disebarkan kepada masyarakat umum, sebagaimana dikutip dari Sulistiyani (2006: 50-51) tentang adanya eksklusifisme terhadap bahasa Arab, yaitu anggapan-anggapan buruk tentang bahasa Arab oleh masyarakat umum.

\section{Keadaan Psikologi Ketika Belajar Bahasa Arab}


Jurnal DinamikA

Volume 1 No. 2 (2020)

E-ISSN: 2723-1410

Website: https://jurnal.iainsalatiga.ac.id/index.php/dinamika/index

Bahasa Arab adalah salah satu pelajaran yang dianggap sulit. Dari kuesioner yang telah disebar diperoleh berbagai keadaan psikologis yang beragam di mana 9 orang menganggap bahwa belajar bahasa Arab itu susah/rumit, 2 orang mengatakan bosan, 22 orang mengatakan bahwa belajar bahasa Arab itu butuh waktu yang lama, 4 orang mengatakan mudah, 17 orang mengatakan asyik, dan 4 orang mengatakan bahwa hanya butuh waktu singkat untuk dapat memahami pelajaran bahasa Arab.

\begin{tabular}{|l|c|}
\hline \multicolumn{1}{|c|}{ Jawaban } & Jumlah \\
\hline Susah/rumit & 9 \\
Membosankan & 2 \\
Butuh waktu & 22 \\
lama & 4 \\
Mudah & 17 \\
Mengasyikkan & 4 \\
Hanya butuh \\
waktu singkat
\end{tabular}

Tabel 1. Perolehan keadaan psikologis responden ketika belajar bahasa Arab.

\section{Subjek yang Dianggap Berpengaruh dalam Pembelajaran Bahasa Arab}

Ada berbagai macam faktor yang mempengaruhi motivasi belajar. Dalam kuesioner yang disebar, peneliti hanya memberikan dan memfokuskan 2 opsi subjek pengaruh yaitu guru dan materi pelajaran serta opsi tambahan yang menggabungkan keduanya, maka diperoleh 3 orang mengatakan bahwa yang menyebabkan bahasa Arab itu mudah atau sulit untuk dipelajari adalah materinya, 14 orang mengatakan disebabkan oleh gurunya, dan 19 orang mengatakan keduanya, baik materi dan guru mempengaruhinya. 


\begin{tabular}{|l|l|}
\hline \multicolumn{1}{|c|}{ Jawaban } & Jumlah \\
\hline Materi & 3 \\
Guru & 14 \\
Materi dan Guru & 19 \\
\hline
\end{tabular}

Tabel 2. Perolehan tanggapan responden tentang subjek yang dianggap berpengaruh dalam pembelajaran bahasa Arab.

\section{Tanggapan Jika Bahasa Arab Diasumsikan Mudah}

Salah satu cara yang digunakan untuk menarik minat motivasi belajar adalah dengan memberikan sugesti atau doktrin. Dalam kuesioner ini peneliti mengajukan sugesti bahwa bahasa Arab itu mudah, dan ternyata diperoleh 16 orang mengatakan setuju, 7 orang tidak setuju, dan 13 orang lainnya menjawab terserah.

\begin{tabular}{|l|l|}
\hline \multicolumn{1}{|c|}{ Jawaban } & Jumlah \\
\hline Setuju & 16 \\
Tidak setuju & 7 \\
Terserah & 13 \\
\hline
\end{tabular}

Tabel 3. Perolehan tanggapan responden jika bahasa Arab diasumsikan mudah.

5. Wawasan Orang Mengenai Al-Qur'an adalah Berbahasa Arab dan Bahasa Arab Adalah Salah Satu Bidang Keilmuan yang Mendapat Jaminan Kemudahan dari Allah

Hampir dari semua responden menjawab bahwa mereka sudah mengetahui bahwa Al-Qur'an adalah berbahasa Arab yaitu dengan persentase 97,2\% dan hanya 1 orang yang menjawab belum. Sementara itu, ketika responden disuguhkan dengan Al-Qur'an surah Al-Qamar yang artinya “Dan 
Jurnal DinamikA

Volume 1 No. 2 (2020)

E-ISSN: 2723-1410

Website: https://jurnal.iainsalatiga.ac.id/index.php/dinamika/index

sesungguhnya telah Kami mudahkan Al-Qur'an untuk pelajaran, maka adakah orang yang mengambil pelajaran?" maka 30 orang menjawab sudah mengetahui ayat tersebut dan hanya 6 orang yang belum mengetahui.

\section{Pembahasan}

\section{Perspektif Tentang Bahasa Arab}

Salah satu hal yang mempengaruhi motivasi belajar adalah perspektif atau sudut pandang dan sugesti mengenai sesuatu. Sugesti merupakan sebuah kata serapan yang berasal dari bahasa Inggris suggestion. Secara umum, sugesti dapat didefinisikan sebagai pengaruh psikis yang datang kepada seorang individu yang bisa datang dari diri sendiri maupun dari orang lain tanpa adanya daya kritik dari individu tersebut (Samuel, 2016). Di Indonesia, pelajaran bahasa Arab termasuk pelajaran yang minim peminat, terlebih lagi pelajaran ini hanya dikhususkan pada lembaga dan institusi yang berada di bawah naungan Kemenag atau lembag islami seperti pondok dan madrasah. Maka tidak mengherankan jika pelajaran itu menimbulkan kontra bagi para pembelajar transisi yaitu misalnya mereka yang dari sekolah dasar umum ingin melanjutkan ke madrasah tsanawiyah atau masuk pondok pesantren.

Ada yang menganggap bahwa bahasa Arab itu sulit karena merupakan sesuatu yang baru untuk mereka yang pemula dan anggapan-anggapan buruk lainnya. Bahkan yang lebih parahnya ada yang mengganggap bahwa bahasa Arab hanya diwajibkan kepada mereka yang akan bergelut di dunia dakwah dan ilmu agama, serta anggapan aneh lainnya yang mengatakan bahwa jika salah dalam melafadzkan huruf Arab akan mendapat dosa (Sulistiyani, 2006:49). Anggapan-anggapan seperti inilah yang harus dihilangkan karena anggapan (dhzan) itu pengaruhnya sangat besar, apa yang kita pikirkan akan menjadi penggerak tindakan yang akan dilakukan, bahkan dalam sebuah hadits disebutkan:

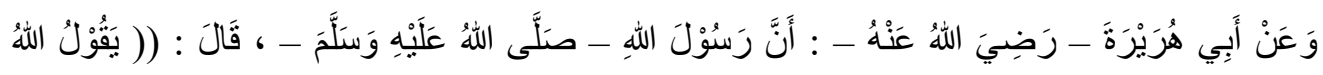

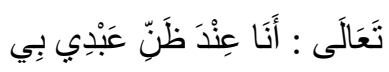


Dari Abu Hurairah radhiyallahu 'anhu, ia berkata bahwa Nabi shallallahu 'alaihi wa sallam bersabda, "Allah Ta'ala berfirman: Aku sesuai persangkaan hamba-Ku... [HR. Bukhari, no. 6970 dan Muslim, no. 2675]

Selain itu juga, kita harus mengabaikan para pesimisme yang mengampanyekan perspektif negatif tentang bahasa Arab seperti kalimat “jangan ambil prodi bahasa Arab, berat. Kamu nggak akan kuat!". Padahal bahasa Arab adalah pelajaran yang sesungguhnya telah mendapat jaminan kemudahan langsung dari Allah, sebagaimana firmanNya dalam surah Maryam/19:97

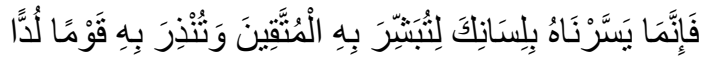

"Maka sesungguhnya telah Kami mudahkan Al- Qur'an itu dengan bahasamu, agar kamu dapat memberi kabar gembira dengan Al-Qur'an itu kepada orang-orang yang bertakwa, dan agar kamu memberi peringatan dengannya kepada kaum yang membangkang."

Allah telah menurunkan syariat ini dengan kehendak terbaik, maka tidak mungkin Allah mempersulit syariatnya karena agama ini mudah.

"Sesungguhnya agama Islam itu mudah." (HR. Bukhari no. 39).

Pada ayat yang lainnya, Allah menjamin kemudahan bahasa Arab bahkan menyebutkannya berulang dengan redaksi yang sama yaitu dalam surah Al-Qamar/54 ayat 17, 22, 32, dan 40.

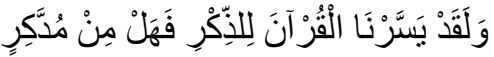

"Dan sesungguhnya telah Kami mudahkan Al Qur'an untuk pelajaran, maka adakah orang yang mengambil pelajaran?"

Jika Allah sang Maha Pencipta sudah menjajikan Al-Qur'an yang berbahasa Arab itu mudah, maka harus kita yakini dan kita berusaha dalam mempelajarinya. Bahasa Arab memang harus dikampanyekan sebagai sebuah ilmu yang mudah, bukan karena hanya iming-iming sebagai alat komunikasi internasional namun juga penting untuk mempertahankan eksistensi agama 
Jurnal DinamikA

Volume 1 No. 2 (2020)

E-ISSN: 2723-1410

Website: https://jurnal.iainsalatiga.ac.id/index.php/dinamika/index

Islam, karena jika kita paham bahasa Arab maka hal itu bukan hanya menjadi jendela tapi pintu dari setiap kebahagian dunia dan akhirat.

\section{Problematika Bahasa Arab dari Sisi Psikologis dan Metodologis}

Bahasa Arab adalah salah satu pelajaran yang dicap sebagai pelajaran rumit dan memiliki banyak problem di dalamnya. Sebagian penyair berkata: "Nahwu itu sulit dan tangga naiknya itu panjang..." Maka Muhammad Ibn Shalih Al-Utsaimin dalam kitabnya Syarh Al-Ajurumiyyah (2005: 10) menjawab "Hal itu tidak benar dan kita tidak sepakat terhadap ungkapan tersebut, justru sebaliknya kita berpendapat insyaaAllah nahwu itu mudah, tangga naiknya juga pendek, dan tingkatannya mudah, dan kita bisa memahaminya dari awal belajar".

Kesulitan belajar bahasa Arab justru dipengaruhi oleh sisi psikologis dan metodologis (Imamuddin, 2018). Sisi psikologis dapat berasal dari persepsi yang mengatakan bahwa bahasa Arab itu sulit dan rendahnya motivasi dari dalam diri pembelajar itu sendiri. Padahal persepsi dan motivasi adalah modal utama yang dibutuhkan oleh pembelajar. Dr. Muhbib Abdul Wahab, M.Ag dalam Webminar Nasional tahun 2020 dengan tema "Pembelajaran Bahasa Arab di Era Tatanan Baru untuk Menyongsong Program Merdeka Belajar” mengatakan bahwa belajar itu diibaratkan seperti segitiga.

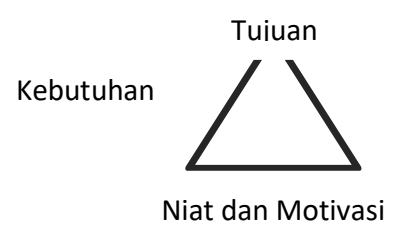

Gambar 1. Segitiga Belajar

Niat dan motivasi menjadi pondasi dalam proses belajar, kalau bukan karena niat yang kokoh maka sudah pasti dalam waktu yang singkat akan malas untuk mengikuti kelanjutan proses belajar. Di samping itu, kebutuhan akan belajar menjadi pendorong dan penopang niat bagi pembelajar untuk sampai pada puncak proses pembelajaran yaitu tujuan. Belajar tanpa adanya niat/motivasi dan kebutuhan tidak akan dapat mencapai pada tujuan belajar. Selain itu juga, sejak pertemuan pertama proses pembelajaran, guru atau pengajar harus 
mampu memberikan kesan belajar yang menarik bagi peserta didiknya dengan menggunakan metodologi pembelajaran dan tata cara mengajar yang kreatif. Metodologi yang kurang tepat akan mengakibatkan proses pembelajaran akan menjadi lama dan pembelajar telah banyak menghabiskan waktunya untuk belajar namun ia belum mendapatkan apa-apa atau belum mencapai tujuan belajar. Syeikh Faras (2008: 18) mengatakan bahwa yang menyebabkan أن الخلل سببه الجهل بطر ائق التعليم والتعلم kesalahan dalam menuntut ilmu adalah (kesalahannya adalah disebabkan oleh ketidaktahuannya terhadap metode pengajaran dan metode belajar).

Pada awal proses pembelajaran bahasa Arab, pengajar seharusnya memulai pembelajaran dengan istima' (mendengarkan) bukan dengan qira'ah (mengeja-membaca) atau kitabah (menulis) karena prinsipnya sama seperti bayi yang baru belajar berbicara, ia harus banyak mendengar terlebih dahulu sehingga dalam akalnya akan menerima rangsangan yang menjadi bahan pemikirannya yang kemudian lahir sebagai pengetahuan. Selain itu juga, pengajar harus memperhatikan kapasitas kemampuan peserta didiknya, jika peserta didiknya adalah al-mubtadi'un (pemula) maka jangan sampaikan kepada mereka materi-materi yang sulit. Syeikh Faras (2008: 31) mengutip pendapat Imam Asy-Syathibi yang mengatakan bahwa salah satu adab guru adalah tidak boleh menyebutkan materi untuk penuntut ilmu tingkat akhir kepada penuntut ilmu yang masih pemula. Kemudian, di antara tips belajar yang baik adalah belajar sedikit-sedikit namun terus-menerus, sebagaiamana Allah menurunkan Al-Qur'an kepada Nabi Muhammad shallallahu 'alaihi wasallam dengan berangsur-angsur agar lebih menetap di hati dan pikiran. Sebagaimana disebutkan dalam surah Al-Furqan/25:32

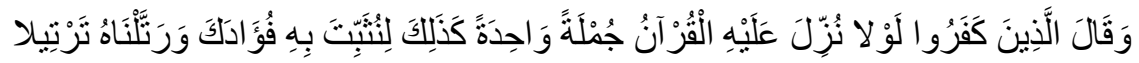

"Berkatalah orang-orang yang kafir: "Mengapa Al-Qur'an itu tidak diturunkan kepadanya sekali turun saja?". Demikianlah supaya Kami perkuat hatimu dengannya dan Kami membacakannya secara tartil (teratur dan benar)." 
Jurnal DinamikA

Volume 1 No. 2 (2020)

E-ISSN: 2723-1410

Website: https://jurnal.iainsalatiga.ac.id/index.php/dinamika/index

Jadi, subjek yang menjadi pemicu belajar bahasa Arab itu mudah atau sulit adalah diri kita sendiri dan juga kesalahan metode yang digunakan oleh guru atau pengajar dalam proses pembelajaran, bukan materi yang ada dalam pelajaran bahasa Arab.

3. Pentingnya Doktrin dan Label Baru Untuk Mempengaruhi Semangat Belajar Bahasa Arab di Era New Normal

Telah diketahui bahwa salah satu faktor yang paling kuat dalam keberhasilan belajar adalah motivasi. Motivasi memiliki kontribusi dalam menumbuhkan minat pembelajar untuk mempelajari suatu bahasa asing (Islam, 2015: 1). Motivasi dapat diberikan dalam bentuk sugesti. Sujanto (2004: 93) menyatakan bahwa sugesti merupakan rangkaian kata yang disusun dan disampaikan dengan cara, situasi, dan tujuan tertentu untuk mempengaruhi kehidupan seseorang. Sebagai seorang pengajar, dalam menyampaikan materi dituntut untuk memberi apersepsi kepada peserta didiknya. Sugesti berupa kata-kata positif akan sangat mempengaruhi bahkan akan tersimpan lama di pikiran dan perspektif peserta didik. Sebagaimana banyak orang mengatakan bahwa disakiti dengan kata itu lebih lama membekas dibandingkan dengan tamparan atau pukulan yang bisa sembuh hanya dalam beberapa hari.

Tidak diragukan juga bahwa sugesti dengan kata-kata akan lebih dapat memacu semangat belajar peserta didik dibandingkan dengan hanya menggunakan metode. Sebagaimana penelitan yang telah dilakukan oleh Fakultas Ilmu Pendidikan Universitas Pendidikan Ganesha Singaraja Indonesia tentang Penerapan Pemberian Sugesti Positif dengan Model SAVI untuk Meningkatkan Hasil Belajar Matematika Siswa Kelas V yang membawa dampak hasil belajar yang baik bagi peserta didik SD Mutiara Singaraja (Septiani, 2016: 10).

Selain itu, para pegiat dan pengajar bahkan institusi pengamong bidang bahasa Arab juga harusnya berinovasi dengan meluncurkan media pembelajaran yang melabelkan bahwa bahasa Arab itu mudah untuk dipelajari, 
sebagaimana pada penamaan judul buku. Judul buku harus dibuat seunik mungkin agar dapat mensugesti dan memberi pengaruh kepada orang yang melihat atau calon pembaca agar dengannya ia tertarik untuk memliki dan menelaah isi buku tersebut. Beberapa buku bahasa Arab telah ada yang diterbitkan dengan judul unik, seperti buku pembeajaran bahasa Arab untuk jenjang SD/MI yang berjudul "Mudah Bahasa Arab" karya Rahmat Faisyal dan modul pelajaran bahasa Arab untuk SMP di Kota Padang Panjang dengan judul "Al-Arabiyyah Sahlah -Bahasa Arab itu Mudah-" karya Afrinaldi Yunas S.Pd.
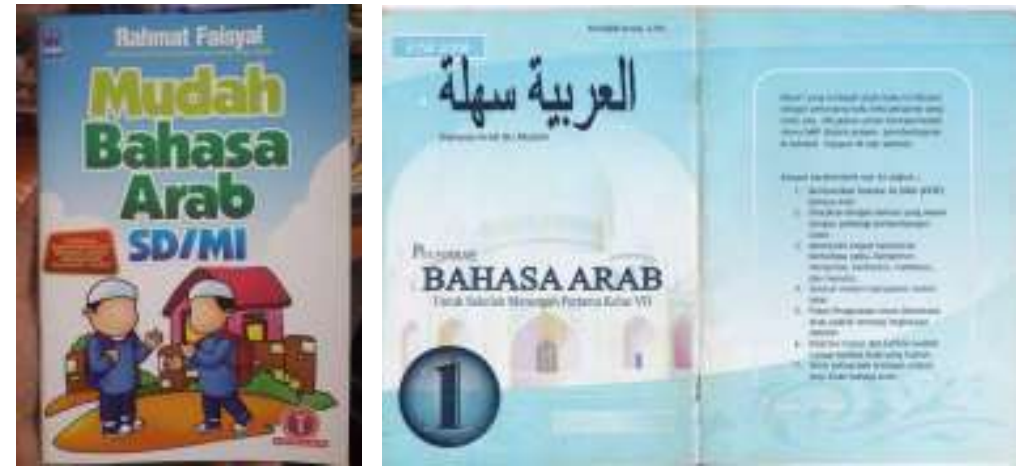

Gambar 2. Buku dan Modul Pembelajaran Bahasa Arab

Kemudian, jargon atau yel-yel juga bisa dipakai untuk sarana ice breaking saat proses belajar mengajar di kelas, sebagaimana yang diterapkan oleh UKM Ittaqo IAIN Salatiga dengan gerakan dan lafal unik:

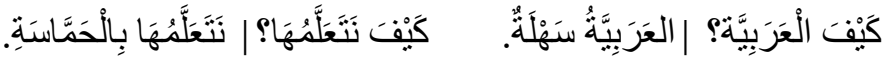

Pada penelitian yang telah dilakukan, 16 orang menyatakan setuju jika ada yang mengatakan bahwa bahasa Arab itu mudah, dan 13 lainnya tidak mempersalahkan jika ada yang berpendapat bahwa bahasa Arab itu mudah serta 30 orang juga telah mengethaui bahwa sebenarnya Al-Qur'an yang berbahasa Arab itu sudah dijamin kemudahannya oleh Allah. Hal ini berarti ada peluang besar bagi para guru atau pengajar untuk menggaungkan bahwa bahasa Arab itu mudah karena responden atau peserta didik tidak terlalu mempermasalahkan tentang suatu perspektif. Jika bukan dari orang-orang yang sekarang membidangi bahasa Arab yang menggencarkan perspektif bahwa 
Jurnal DinamikA

Volume 1 No. 2 (2020)

E-ISSN: 2723-1410

Website: https://jurnal.iainsalatiga.ac.id/index.php/dinamika/index

bahasa Arab itu mudah, maka siapa lagi? Label baru untuk bahasa Arab harus segera digaungkan, terlebih di masa-masa kritis seperti sekarang. Pembelajaran daring menjadi tantangan bagi para guru dan pengajar. Mereka dituntut untuk tetap bisa menyampaikan materi pelajaran dengan cara yang kreatif walaupun suasananya berbeda dengan sebelumnya yang berlangsung dengan tatap muka. Maka sejalan dengan itu, bahasa Arab juga harusnya lahir dengan new label dan new perspective yaitu Al-Arabiyyah Sahlah (Bahasa Arab itu Mudah).

\section{Kesimpulan}

Bahasa Arab telah dicap sebagai pelajaran yang susah dan rumit. Walaupun demikian, semua orang sudah mengetahui bahwa Al-Qur'an dan Hadits yang menjadi pedoman hidup adalah berbahasa Arab. Maka dengan dasar ini, kita menjadikannya landasan bahwa meskipun sulit namun tetap penting dan wajib diusahakan untuk mempelajarinya karena bahasa Arab menjadi alat untuk memahami syariat Islam. Perspektif bahwa bahasa Arab itu sulit harus dihapuskan dari benak pikiran mereka yang sedang mempelajarinya, karena hal tersebut sangat merugikan, karena segala apa yang dipikirkan akan menjadi penggerak dalam bertindak, jika dalam diri telah tertanam perspektif bahwa bahasa Arab itu sulit maka akan timbul rasa malas dan enggan untuk mempelajarinya, begitupun sebaliknya. Maka diperlukan perbaikan dan label baru untuk mengatasi hal tersebut. Al-Arabiyyah Sahlah cocok untuk dikampanyekan dan diharapkan mampu menjadi label dan perspektif baru di era new normal ini, 


\section{Saran}

1. Kepada para pembelajar pemula bahasa Arab, hendaknya lebih menanamkan persepsi bahwa bahasa Arab itu adalah ilmu yang telah mendapat jaminan kemudahan dari Allah maka diperlukan kesungguhan dan kesabaran dalam mempelajarinya.

2. Kepada para pembelajar tingkat akhir bahasa Arab, hendaknya tidak menimbulkan kesan buruk dan memberikan rasa pesimis kepada pembelajar pemula tentang bahasa Arab, justru pembelajar tingkat akhir adalah harapan untuk dapat menjadi agen pembaharu dan penyemangat.

3. Kepada semua pihak yang bernaung di bidang bahasa Arab, hendaknya terus meningkatkan kualitas metode mengajarnya dan berinovasi untuk menciptakan karya-karya yang dapat memajukan eksistensi bahasa Arab.

\section{Daftar Referensi}

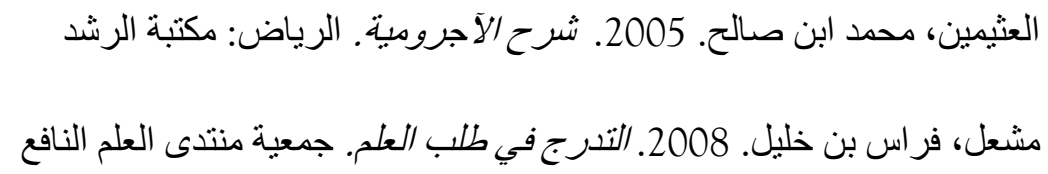

Imamuddin. 2018. Hentikan Perspektif Belajar Bahasa Arab yang Sulit. https://www.kompasiana.com/al-

khaliqy/5bf67ad443322f68a427bc13/hentikan-perspektif-belajar-bahasa-aranyang-sulit diakses 26 Agustus 2020

Islam, Asep Muhammad Saepul. 2015. Faktor Demotivasi Pembelajaran Bahasa Arab. Arabiyat 2(1), 1-16.

Samuel. 2016. Sugesti Diri untuk Hal Positif. Universitas Ciputra Surabaya http://ciputrauceo.net/blog/2016/2/1/sugesti-diri-untuk-hal-positif diakses 26 Agustus 2020

Septiani, N. D. dkk. (2016). Penerapan Pemberian Sugesti Positif Dengan Model Savi Kelas V. Universitas Pendidikan Ganesha. 
Jurnal DinamikA

Volume 1 No. 2 (2020)

E-ISSN: 2723-1410

Website: https://jurnal.iainsalatiga.ac.id/index.php/dinamika/index

Sulistiyani, F. (2006). Pendidikan Bahasa Arab (Antara Eksklusifisme dan Inklusifisme ). Al-Arabiyah, 2(2), 50-71.

Susilana, Rudi, M., Johan, R., \& Si, M. (2012). Penelitian Pendidikan. Jakarta Pusat: Kementerian Agama RI

Tuasikal, Muhammad Abduh. 2013. Ajaran Islam Tidak Membuat Susah. https://rumaysho.com/3150-ajaran-islam-tidak-membuat-susah.html diakses 26 Agustus 2020

. 2018. Aku Sesuai Persangkaan Hamba-Ku Hingga Balasan Mengingat Allah. https://rumaysho.com/17041-aku-sesuai-persangkaanhamba-ku-hingga-balasan-mengingat-allah.html diakses 26 Agustus 2020

Ukkasyah, Sa'id Abu. 2017. Keistimewaan Bahasa Arab (7). https://muslim.or.id/31351;keistimewaan-bahasa-arab-7.html diakses 26 Agustus 2020 